\title{
Optimizing the Air Dissolution Parameters in an Unpacked Dissolved Air Flotation System
}

\author{
Adam Dassey ${ }^{1,2}$ and Chandra Theegala ${ }^{1,2, *}$ \\ 1 Department of Biological and Agricultural Engineering, Louisiana State University, 161 EB Doran \\ Bldg., Baton Rouge, LA 70803, USA; E-Mail: adasse1@1su.edu \\ 2 Louisiana State University Agriculture Center, Baton Rouge, LA 70894, USA \\ * Author to whom correspondence should be addressed; E-Mail: ctheegala@agcenter.lsu.edu; \\ Tel.: +1-225-578-1060; Fax: +1-225-578-3492.
}

Received: 22 November 2011; in revised form: 19 December 2011 / Accepted: 22 December 2011 / Published: 27 December 2011

\begin{abstract}
Due to the various parameters that influence air solubility and microbubble production in dissolved air flotation (DAF), a multitude of values that cover a large range for these parameters are suggested for field systems. An unpacked saturator and an air quantification unit were designed to specify the effects of power, pressure, temperature, hydraulic retention time, and air flow on the DAF performance. It was determined that a pressure of $621 \mathrm{kPa}$, hydraulic retention time of $18.2 \mathrm{~min}$, and air flow of $8.5 \mathrm{~L} / \mathrm{h}$ would be the best controlled parameters for maximum efficiency in this unit. A temperature of $7{ }^{\circ} \mathrm{C}$ showed the greatest microbubble production, but temperature control would not be expected in actual application. The maximum microbubble flow from the designed system produced $30 \mathrm{~mL}$ of air $( \pm 1.5)$ per $\mathrm{L}$ of water under these conditions with immediate startup. The maximum theoretical dissolved air volume of $107 \mathrm{~mL}( \pm 6)$ was achieved at a retention time of $2 \mathrm{~h}$ and a pressure of $621 \mathrm{kPa}$. To isolate and have better control over the various DAF operational parameters, the DAF unit was operated without the unsaturated flow stream. This mode of operation led to the formation of large bubbles at peak bubble production rates. In a real-world application, the large bubble formation will be avoided by mixing with raw unsaturated stream and by altering the location of dissolved air output flow.
\end{abstract}

Keywords: air quantification; dissolved air flotation; efficiency; microbubble production 


\section{Introduction}

The design of a specific dissolved air flotation (DAF) system depends upon the factors such as the volume of wastewater to be treated, the degree and nature of contamination, the extent of treatment required, and any subsequent treatment that is required for the recovered product concentration [1]. These factors, in turn, indicate the appropriate dissolution pressure, flow rate, retention time, recycle ratio, coagulant and flocculent pretreatment, flotation tank design, and baffle setup for the desired treatment. Despite the widespread acceptance and industrial use of the DAF technology, many questions pertinent to the functionality and optimization remain unanswered. Many design references commonly used by engineers and designers provide wide ranges in data, or no data at all, for these common design parameters $[2,3]$.

One of the common design parameters most often used for sizing a dissolved air flotation unit is the recycle ratio. The recycle ratio $\left(R_{r}\right)$, defined as:

$$
R_{r}=Q_{r} / Q_{w}
$$

where $\left(Q_{r}\right)$ is the air saturated recycle flow and $\left(Q_{w}\right)$ is the waste flow, is used as a standard measure of the air supplied by a dissolved air flotation unit [4]. Depending on air solubility and the concentration of solids in the waste flow, recycle ratios vary anywhere from 10 to $100 \%$ [5]. Lower recycle ratios indicate a more efficient system since less recycle flow is required to treat the waste flow [6]. Minimizing the amount of recycle flow in a system can be achieved by maximizing bubble production so as to increase the capture efficiency.

Capture efficiency is defined as the ratio of the number of bubble-captured particles to the number of particles initially located in the volume that the bubbles swept [7]. As the bubble concentration increases, the collision opportunity between bubble and particle also increases, thereby, leading to improved attachment efficiency [8]. The efficiency of a DAF, therefore, is directly proportional to the bubble concentration which is generated by the dissolved gas in the saturator.

The equilibrium concentration of a dissolved gas depends mainly upon the temperature of the water and partial pressure of the gas in the atmosphere in contact with the water [9]. In a pressure saturator, however, the hydraulic retention time and air input volumes are also important factors. The objective of this research was to determine the most effective pressure, temperature, retention time, and air input volume that would provide the greatest microbubble production for maximum operation efficiency.

\section{Materials and Methods}

\subsection{DAF Design}

The recycle-flow pressurization design was used in the construction of this bench scale DAF unit (Figure 1). Tap water was pressurized so that the effects of pressure, temperature, retention time, and air flow on microbubble production could be assessed.

The dissolution tank was made with a $1.37 \mathrm{~m}$ long, $15.24 \mathrm{~cm}$ inner diameter (I.D.) stainless steel pipe with welded end caps to form an airtight tank with a $25.57 \mathrm{~L}$ volume. One port at the top of the cap accommodated a pressure gauge and continuous pressure release valve which allowed the system to maintain any set pressure ranging from 0 to $689 \mathrm{kPa}$, by bleeding off any excess air. 
Figure 1. Dissolved air flotation (DAF) Setup. The dissolution tank was pressurized with separate flows of water and air entering the base of the unit. Each parameter was controlled independently of the rest.

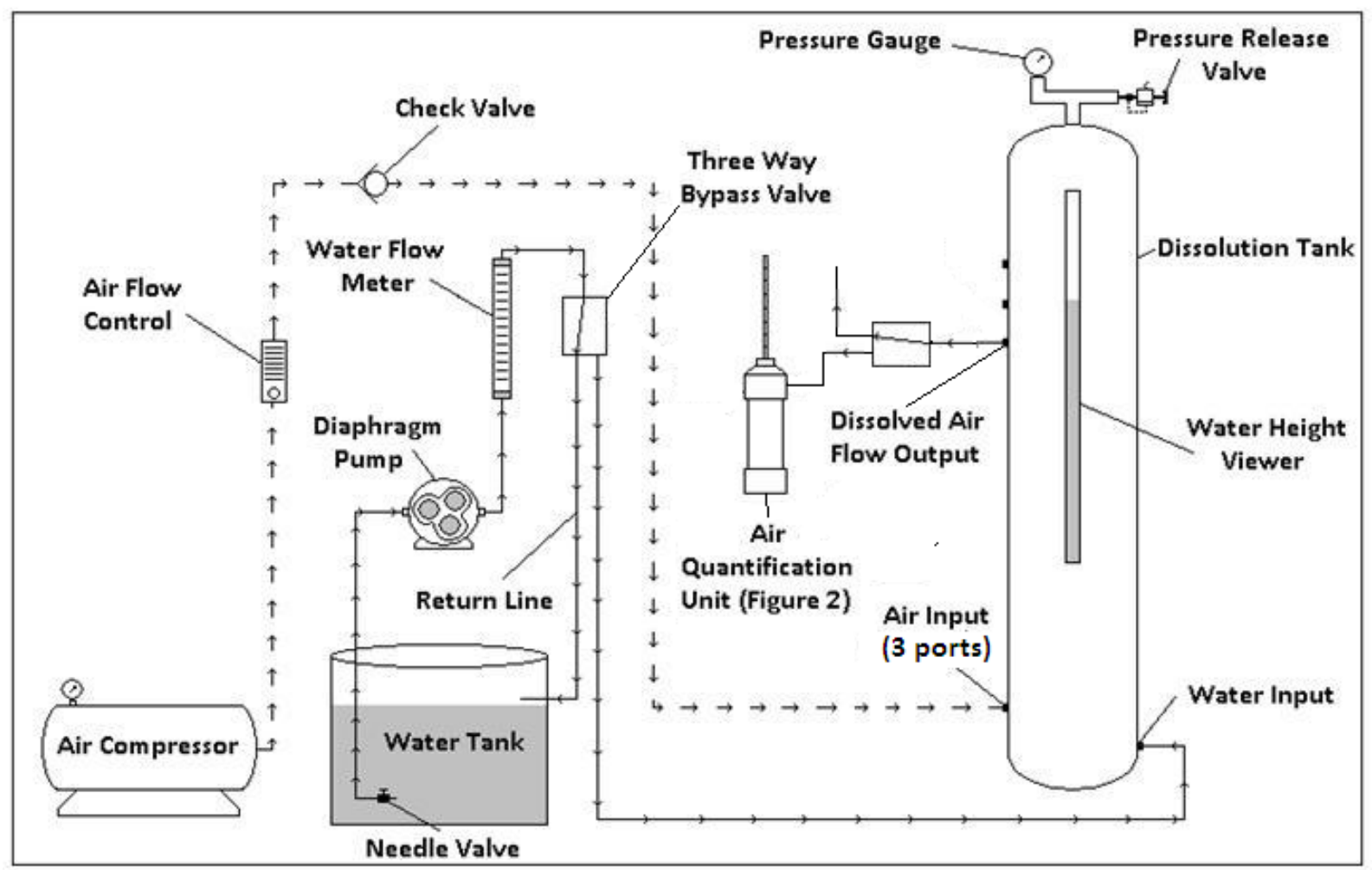

A diaphragm pump was used to push water into the dissolution tank at high pressures through one port at the bottom of the tank. A needle valve submerged within the clean water tank adjusted the inflow of the pump which was measured with an inline flow meter.

Three additional ports, separated by $120^{\circ}$ (when observed from the top), were used for air injection through three fine air stones $(3.81 \mathrm{~cm} \times 1.27 \mathrm{~cm} \times 1.27 \mathrm{~cm})$. Air dissolution is enhanced at the water/air interface by setting up an air injection system below the water surface [10]. A flow control meter was placed in-line between an air compressor and the dissolution tank for air adjustment.

\subsection{Quantification of Dissolved Air}

Understanding how the various parameters of the saturator affected air solubility was possible by quantifying the excess air volume that formed microbubbles. All gas solubility laws and fundamental thermodynamic principles governing gas solubility will govern micro bubble production. The excess dissolved air volume beyond atmospheric saturation is more important than the total air volume leaving the system [11]. The quantification of excess air volume was accomplished by measuring the volume of air that was released after depressurization with a simple volume displacement system (Figure 2).

The measuring unit body consisted of a clear $7.62 \mathrm{~cm}$ I.D. PVC pipe that was capped on the bottom end and reduced at the top to a $1.27 \mathrm{~cm}$ national pip thread (NPT) coupling with a reducer. The volume was capable of holding over $1 \mathrm{~L}$ of water. A $1.27 \mathrm{~cm}$ NPT male with $1.59 \mathrm{~cm}$ O.D. barb was connected to a graduated $1.59 \mathrm{~cm}$ I.D. Tygon tubing and was screwed into the top reduced coupling. The tubing 
was marked up to $100 \mathrm{~mL}$ in increments of $10 \mathrm{~mL}$. Raising the outlet tube to the height of the system prevented the drainage of the system when not in use. Steinbach and Haarhoff recommend using a similar system for measuring the precipitated air volume with a batch system; however several adjustments were made for simplicity and to improve the accuracy [12].

Figure 2. The air quantification unit measured the volume of air that was released from solution exiting the dissolved flotation unit.

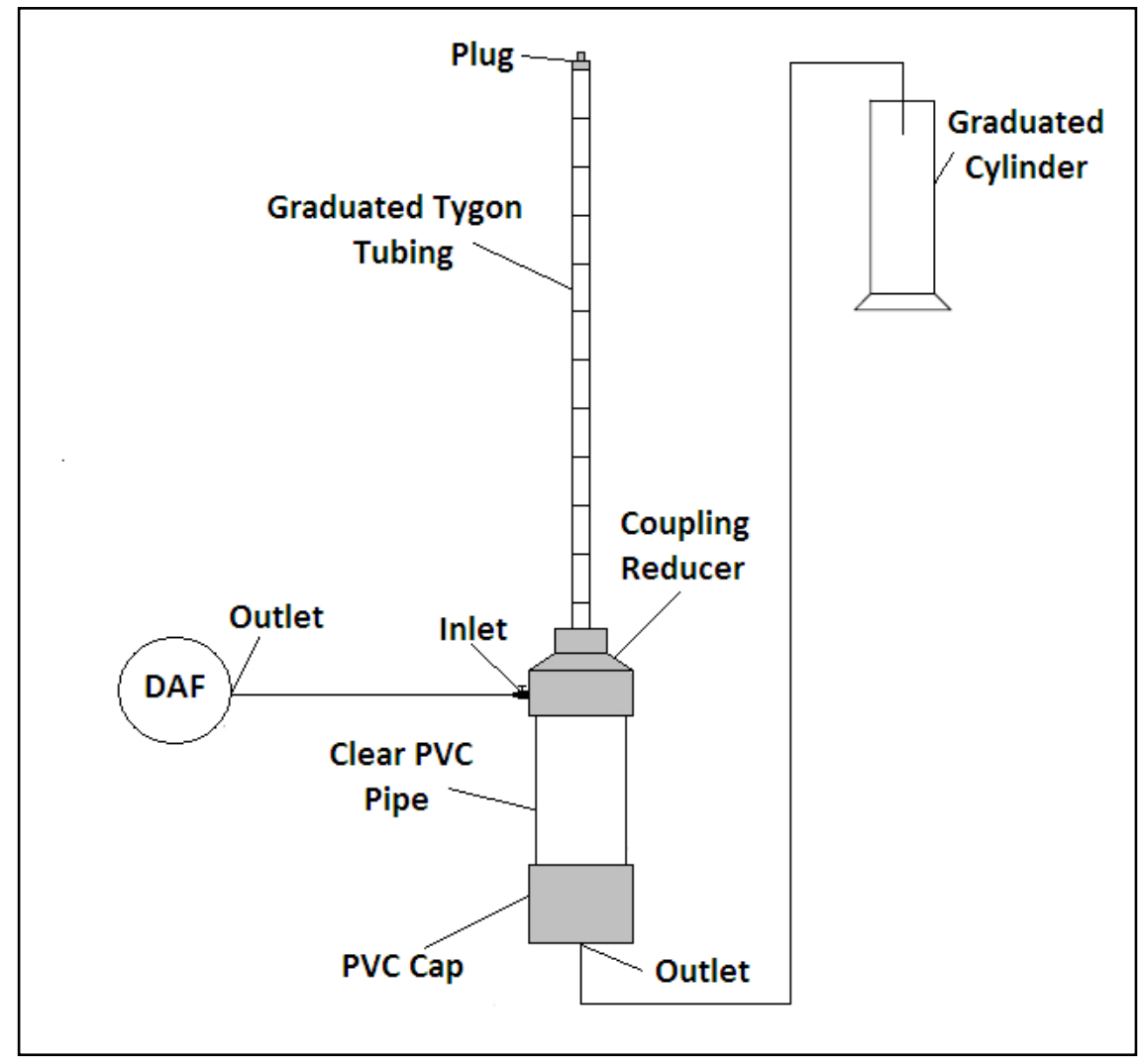

For every measurement taken, the following procedure was followed: With the inlet closed, the plug was removed from the graduated tubing and the air quantification unit was filled with water so that the water level of the outlet hose and brim of the graduated tubing were even. The $0.95 \mathrm{~cm}$ I.D. outlet tubing remained open to the atmosphere and was dropped into a graduated cylinder, which was elevated to an appropriate height to maintain the static water levels. After filling up the air quantification unit and the graduated tubing with water, the $1.59 \mathrm{~cm}$ I.D. tubing was plugged with a rubber stopper to prevent any air release. When ready, the inlet valve was opened to allow the air saturated flow from the DAF system into the measuring unit. The water volume was displaced by the incoming air and water and exited the bottom of the unit where it was measured in the graduated cylinder. When $1 \mathrm{~L}$ of water was collected in the graduated cylinder, the flow from the DAF unit was turned off. The air that was released from solution rose through the graduated tubing where its total volume was measured. After waiting $5 \mathrm{~min}$ to ensure that all the air had released from solution, the plug at the top was removed to equalize the pressure of the system. The volume of air per L of water was measured by reading the volume displaced in the graduated tygon tubing. 


\subsection{Process Variables Testing}

\subsubsection{Pressure}

The pressure regulator at the top of the saturation tank allowed the pressure to be sustained at 345 , $414,483,552$, and $621 \mathrm{kPa}$. The water flow rate was maintained at $1.8 \mathrm{~L} / \mathrm{min}$ for a hydraulic retention time (HRT) of $11 \mathrm{~min}$. The temperature was held at $21^{\circ} \mathrm{C}$ and the air flow was kept steady at $8.5 \mathrm{~L} / \mathrm{h}$.

The energy efficiency at various pressures was determined by measuring the power consumption of the pump with a watt meter (P3 Kill A Watt Load Meter) and comparing that value with bubble production previously determined. The meter displayed the watts that were consumed by the pump as the pressure in the dissolution tank increased from 0 to $621 \mathrm{kPa}$.

\subsubsection{Temperature}

Ice and water heaters were used to vary the water temperatures from $7,14,21,28$, and $35{ }^{\circ} \mathrm{C}$. The water flow rate was maintained at $1.8 \mathrm{~L} / \mathrm{min}$ for a HRT of $11 \mathrm{~min}$. The pressure remained constant at $552 \mathrm{kPa}$ and the air flow was sustained at $8.5 \mathrm{~L} / \mathrm{h}$.

\subsubsection{Hydraulic Retention Time}

The water flow rates were varied at $0.8,1.3,1.8,2.3$, and $2.8 \mathrm{~L} / \mathrm{min}$. These flows corresponded to $25,15.4,11.1,8.7$, and $7.1 \mathrm{~min}$ retention times in the dissolution tank, respectively. The temperature was held at $21^{\circ} \mathrm{C}$ and the air flow was steady at $8.5 \mathrm{~L} / \mathrm{h}$. The pressure remained constant at $552 \mathrm{kPa}$.

\subsubsection{Air Flow}

An air flow meter varied the incoming air at $0,5.7,11.3,17,22.7 \mathrm{~L} / \mathrm{h}$. The water flow rate was maintained at $1.8 \mathrm{~L} / \mathrm{min}$ for a HRT of $11 \mathrm{~min}$, and the pressure was maintained at $552 \mathrm{kPa}$. The water temperature was noted at $21^{\circ} \mathrm{C}$ and was held constant throughout the test.

\subsubsection{Maximum Production}

A final test was used to determine the maximum bubble concentration that would exit the dissolution tank when supplying additional aeration. The ideal pressure, temperature, hydraulic retention time, and air flow previously determined were held constant. The flow rate was maintained at $1.1 \mathrm{~L} / \mathrm{min}$ for a HRT of $18.2 \mathrm{~min}$. The water temperature was $12{ }^{\circ} \mathrm{C}$ and the pressure of the dissolution tank was maintained at $621 \mathrm{kPa}$. The air flow was held constant at $8.5 \mathrm{~L} / \mathrm{h}$.

After one HRT had passed, the water inflow and outflow were turned off and the system was aerated for an additional $0,5,10,15,20,30,60,120$, and $1,080 \mathrm{~min}$ at a rate of $8.5 \mathrm{~L} / \mathrm{h}$. The pressure release valve prevented an increase in pressure while the system was being aerated. After the allotted time of additional aeration elapsed, the air flow was shut off and the system remained undisturbed for $5 \mathrm{~min}$. The exiting flow line was then connected to the air quantification unit and opened to measure the volume of air per L of water. The system was then allowed to return to startup conditions before the next time of additional aeration was incorporated. 


\section{Results}

\subsection{Pressure}

The largest average volume of air measured per L of water was $19.67 \mathrm{~mL}( \pm 0.58)$ and was achieved at $621 \mathrm{kPa}$ (Figure 3). The best fit curve $\left(\mathrm{R}^{2}=0.975\right)$ followed Henry's Law, which states that the amount of gas that can be dissolved in a given volume of liquid at a constant temperature is directly proportional to the partial pressure of the gas $(P)$, which is given by:

$$
P=K_{c} M
$$

where $\left(K_{c}\right)$ is a variation of Henry's constant as defined by Haarhoff and Steinback for a specified gas and $(M)$ is the molar concentration of the gas in solution [13].

Figure 3. (*) The retention time $(11 \mathrm{~min})$, temperature $\left(21^{\circ} \mathrm{C}\right)$, and air flow $(8.5 \mathrm{~L} / \mathrm{h})$ were held constant. The microbubble volume was measured at pressures of $345,414,483,552$, and $621 \mathrm{kPa}$; (घ)The power consumed by the pump at each pressure was correlated to volume of bubbles produced.

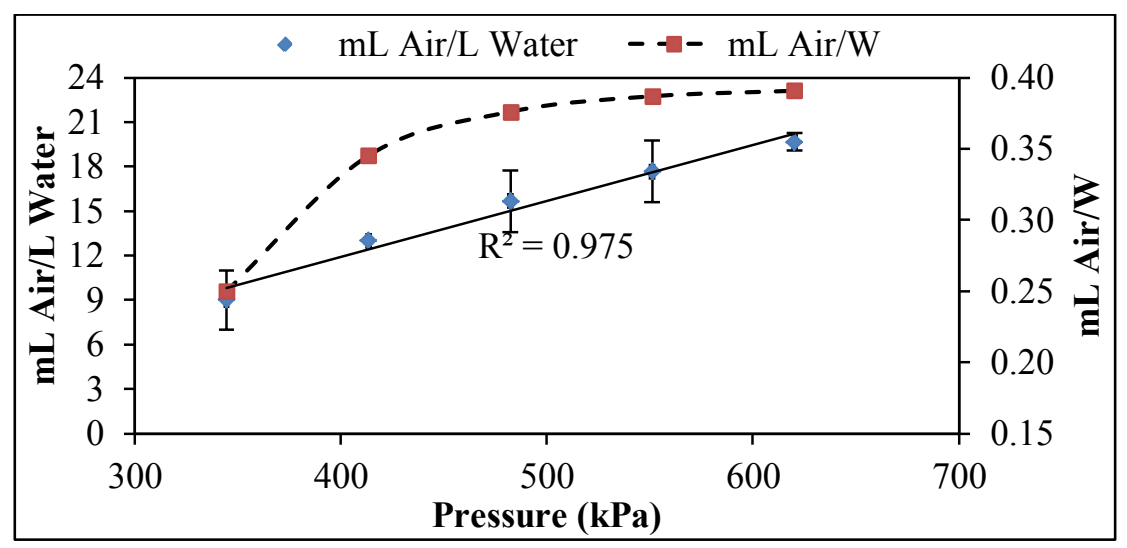

Higher pressures provided greater solubility, but there was a diminishing return in pressures over $500 \mathrm{KPa}$ (73 psi) [14]. Even though the average bubble production increased with the increase in pressure, the deviation between values of 552-621 kPa showed no significant difference $(\mathrm{P}>0.05)$. Without surfactants, the minimum saturation pressure required for dissolution to occur was found to be $304 \mathrm{kPa}$ which explained the lack of significant bubble production at pressures below $350 \mathrm{kPa}$ [15].

\subsection{Power Consumption}

The power consumption of the pump increased linearly as the pressure of the dissolution tank increased from 0 to $621 \mathrm{kPa}$. When the pump ran with atmospheric pressure on its exiting end, it consumed an average of $24 \mathrm{~W}( \pm 0.0)$, and when the dissolution tank reached $621 \mathrm{kPa}$ the pump doubled its power intake to $50.3 \mathrm{~W}( \pm 2.1)$. The values of bubble production and power consumption at various pressures were then compared in to determine the efficiency of the system at increasing pressures. The best fit curve was hyperbolic, with an immediate increase from $345 \mathrm{kPa}$ to $414 \mathrm{kPa}$, and a peak value achieved at $621 \mathrm{kPa}$. Despite the flattening of the curve at the end, $621 \mathrm{kPa}$ was still the most efficient, providing an average of $0.391 \mathrm{~mL}$ of air per $\mathrm{W}$. 
Comparing the results of the bubble production and power consumption tests indicated that operating a DAF system at $621 \mathrm{kPa}$ provided the most air at the lowest energy rate. The flattening of the curve indicated that operating the system above $621 \mathrm{kPa}$ would provide no additional gain in air volume produced per energy usage. Conversely, operating at lower pressures required more energy to achieve the equivalent micro bubble production volume.

\subsection{Temperature}

The bubble production with respect to temperature did not follow as initially expected (Figure 4). Based on established gas laws, the temperature should have an inverse relationship with air solubility, with cooler water temperatures increasing air solubility and warmer temperatures decreasing air solubility. The relationship of Henry's constant and temperature is expressed in the following van's Hoff-type relationship [9].

$$
\log K_{C}=\frac{-H^{o}}{2.3 R T}+K
$$

where

$K_{c}=$ Henry constant

$H^{o}=$ heat absorbed in the evaporation of $1 \mathrm{~mol}$ of gas from solution, $\mathrm{kcal} / \mathrm{kmol}$

$R=$ universal gas constant, $1.987 \mathrm{kcal} / \mathrm{kmol}$

$T=$ absolute temperature, ${ }^{\circ} \mathrm{K}$

$K=$ individual gas constant

Figure 4. The pressure $(552 \mathrm{kPa})$, retention time $(11 \mathrm{~min})$ and air flow $(8.5 \mathrm{~L} / \mathrm{h})$ were held constant. The microbubble volume was measured at temperatures of $7,14,21,28$, and $35^{\circ} \mathrm{C}$.

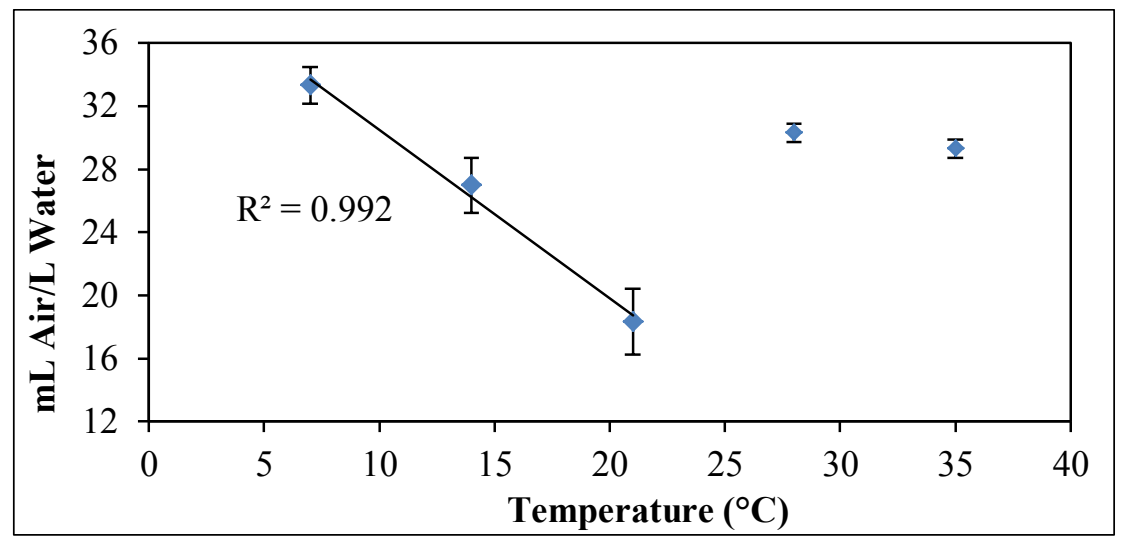

The coolest temperature of $7{ }^{\circ} \mathrm{C}$ provided the greatest air solubility, and the bubble production decreased linearly with increasing temperature up to $21^{\circ} \mathrm{C}$. Further increase in temperature, however, increased the bubble production, leaving two data points well outside the linear curve.

The increased volume of air released from the exiting flow at warmer temperatures can be explained by the Stokes-Einstein equation for diffusivity [16].

$$
D=\frac{k^{\prime} T}{6 \pi \alpha \mu}
$$


where

$D=$ the diffusivity of the gas, $\mathrm{m}^{2} / \mathrm{s}$

$k^{\prime}=$ Bolzmann constant, $1.38 \times 10^{-23} \mathrm{~J} /{ }^{\circ} \mathrm{K}$

$T=$ the absolute temperature, ${ }^{\circ} \mathrm{K}$

$\alpha=$ radius of the solute molecule, $\mathrm{m}$

$\mu=$ viscosity of the solvent, $\mathrm{kg} / \mathrm{m}^{*} \mathrm{~s}$

The rate of transfer of gas between water and air was controlled by the thickness of a thin layer of water through which gas was transferred by molecular diffusion [17]. The increase in temperature was believed to reduce this boundary layer, so that the rate of gas transfer was faster than the transfer at cooler water temperatures. The increased air solubility at cool water temperatures is offset by reduced saturation efficiency at lower temperatures [11]. However, it has to be kept in mind that the effect of the gas transfer rates would diminish with increasing hydraulic retention times; eventually yielding the inverse relationship between the temperature and air solubility.

\subsection{Hydraulic Retention Time}

An increase in water flow rate resulted in a decrease in bubble production (Figure 5). Hydraulic loading had the expected effect on saturator efficiency, namely that higher loading leads to lower bubble production [11]. The limited amount of time for air to dissolve in solution resulted in poor air solubility and bubble production. The slowest flow used was $0.8 \mathrm{~L} / \mathrm{min}$, which provided the greatest amount of dissolved air averaging $25.33 \mathrm{~mL}( \pm 0.58)$. As the flows increased, the retention times decreased, allowing for a shorter time for air to become fully dissolved.

Figure 5. The pressure $(552 \mathrm{kPa})$, temperature $\left(21^{\circ} \mathrm{C}\right)$, and air flow $(8.5 \mathrm{~L} / \mathrm{h})$ were held constant. The microbubble volume was measured at retention times of $25,15.4,11.1,8.7$, and $7.1 \mathrm{~min}$.

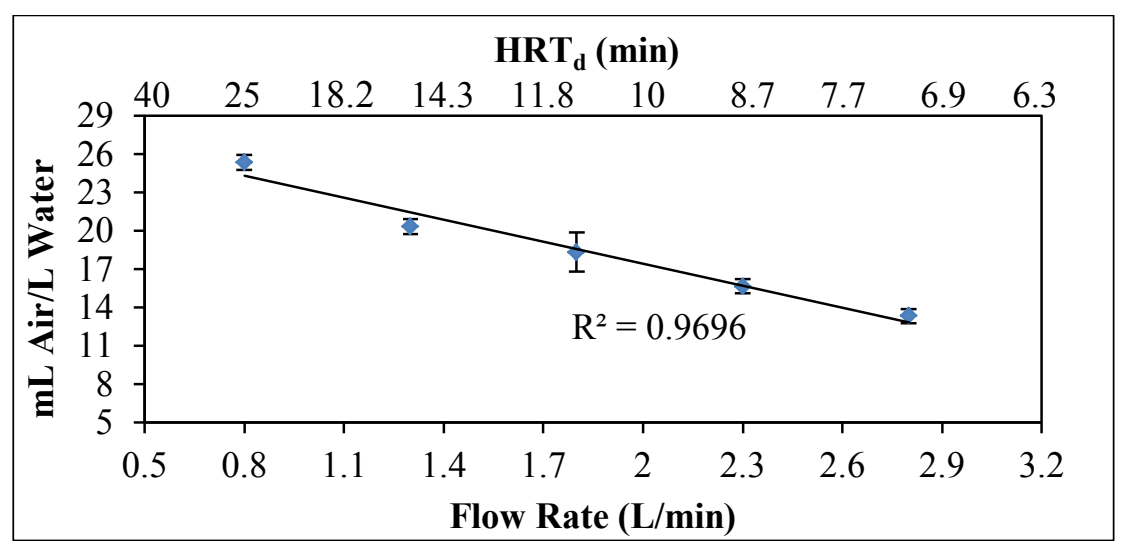

\subsection{Air Flow}

Increasing the air flow beyond the theoretically required air flow $(9.6 \mathrm{~L} / \mathrm{h})$ provided no significant increase in microbubble production (Figure 6). The best fit curve $\left(\mathrm{R}^{2}=0.955\right)$ was hyperbolic as it indicated a maximum bubble production around $17 \mathrm{~L} / \mathrm{h}$ and decreased at $22.7 \mathrm{~L} / \mathrm{h}$. Even though 
$17 \mathrm{~L} / \mathrm{h}$ had the highest bubble production, it showed no statistical variation $(\mathrm{P}>0.05)$ with $22.7 \mathrm{~L} / \mathrm{h}$ and $11.3 \mathrm{~L} / \mathrm{h}$.

Figure 6. The pressure $(552 \mathrm{kPa})$, temperature $\left(21^{\circ} \mathrm{C}\right)$, and retention time $(11 \mathrm{~min})$ were held constant. The microbubble volume was measured at air flow rates of $0,5.7,11.3,17$, $22.7 \mathrm{~L} / \mathrm{h}$.

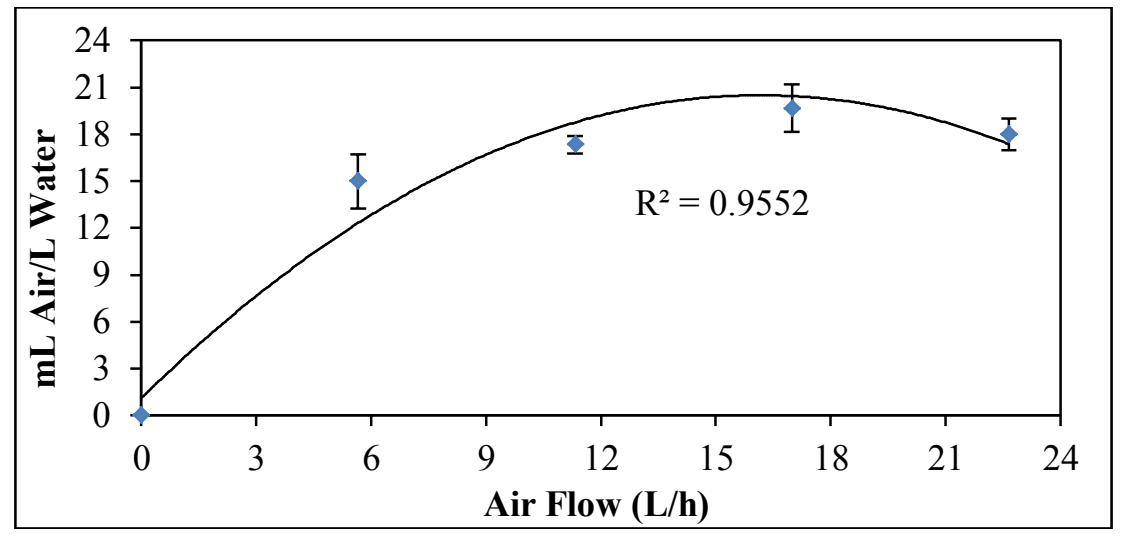

It was also noted that when the air flow was increased beyond $11.3 \mathrm{~L} / \mathrm{h}$, the microbubble flow was disturbed by large bubbles. The increased air input created larger bubbles with smaller specific surface areas and led to poorer gas transfers. Instead of dissolving in solution, these larger bubbles were quickly ejected from the water column and exited with the dissolved air flow. Since these large bubbles had no added value for the flotation process, the incoming air flow was not increased past $11.3 \mathrm{~L} / \mathrm{h}$ for all later experiments. It was determined that the air flow beyond an optimum point negatively impacted the microbubble production.

\subsection{Maximum Bubble Production}

An increasing linear trend was observed with the bubble volume as the time of aeration increased to $20 \mathrm{~min}$ in the batch tests (Figure 7). The best fit curve $\left(\mathrm{R}^{2}=0.763\right)$, however, was hyperbolic since the bubble volume plateaued at 30 and $60 \mathrm{~min}$, and did not reach a maximum volume (around $107 \mathrm{~mL}$ air $( \pm 6)$ per L of water) until $120 \mathrm{~min}(2 \mathrm{~h})$ of aeration. This value was also congruent with the maximum theoretical amount of air that would dissolve at that temperature and pressure $(109 \mathrm{~mL} / \mathrm{L})$.

Immediately after one hydraulic retention time, and without any additional aeration, it was noted that the bubble production was around $30 \mathrm{~mL}$ of air $( \pm 1.5)$ from $1 \mathrm{~L}$ of water. More importantly, the air volume that was measured resulted solely from microbubbles. As the air solubility increased as a result of longer aeration times, the bubbles exiting the flow were much larger in diameter (approximately $2 \mathrm{~mm}$ in diameter as compared to $40 \mu \mathrm{m}$ ). Vlyssides and coworkers indicated a similar problem, stating that during depressurization of water saturated with air, bubbles smaller than $1 \mu \mathrm{m}$ were formed, but through mechanisms not thoroughly understood, they joined and produced a range of bubbles, with sizes between $1 \mu \mathrm{m}$ and a few $\mathrm{mm}$ [18]. Wang and Ouyang indicated that the bubble size distribution was connected with the degree of turbulence caused by the passage of the liquid flow through the valve [19]. Bubble size also increases with the presence of a tube behind the valve [14]. 
However, in a real-world application, mixing the pressurized flow with the unsaturated raw or influent stream is anticipated to lower or eliminate the problems associated with larger bubbles.

Figure 7. The maximum production runs were tested at optimum pressure $(621 \mathrm{kPa})$, temperature $\left(12^{\circ} \mathrm{C}\right)$, and air flow $(8.5 \mathrm{~L} / \mathrm{h})$. After one hydraulic retention time (HRT) had passed, the water inflow and outflow were turned off and the system was aerated for an additional $0,5,10,15,20,30,60,120$, and $1080 \mathrm{~min}$ at a rate of $8.5 \mathrm{~L} / \mathrm{h}$.

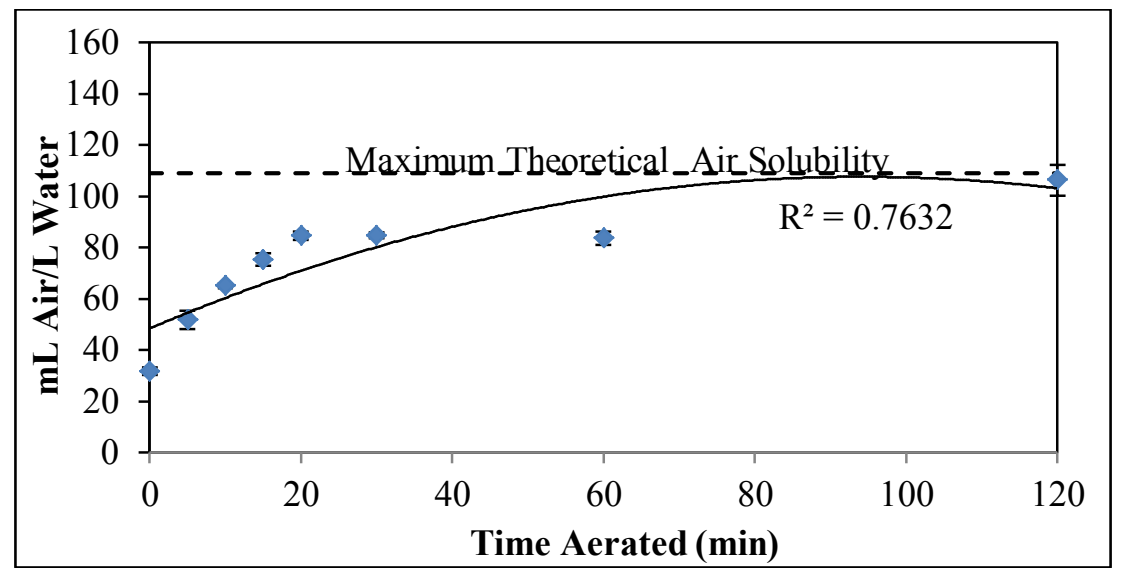

\section{Conclusions}

The air transfer efficiency, plateaued at $\sim 0.391 \mathrm{~mL} / \mathrm{W}$ at dissolution pressures of $621 \mathrm{kPa}$. Although higher pressures provided greater air solubility, there was a diminishing return on transfer efficiency at higher pressures. The effect of temperature on dissolution was mixed, possibly due to two competing processes, namely: 1) reduced gas solubility at higher temperatures, and 2) reduction of boundary layer at higher temperatures. The air flow into the dissolution tank beyond $(11.3 \mathrm{~L} / \mathrm{h})$ negatively impacted the microbubble production due to formation of large bubbles in the water column. Although the optimization runs were limited to $30 \%$ air dissolution due to large bubble formation, $100 \%$ dissolution efficiency was achieved by increasing the aeration time to $2 \mathrm{~h}$. Additional design modifications (position of pressure relief valve, diameter and length of exit tubing) may also help in alleviating the $30 \%$ limitation in a field setting.

\section{References}

1. Telang, A. Waste water treatment systems. In Proceedings of the 22nd WEDC Conference, New Delhi, India, 9-13 September 1996.

2. Chung, T.; Kim, D. Significance of pressure and recirculation in sludge thickening by dissolved air flotation. Water Sci. Technol. 1997, 36, 223-230.

3. Han, M.; Kim, W.; Dockko, S. Collision efficiency factor of bubble and particle in DAF: Theory and experimental verification. Water Sci. Technol. 2001, 43, 139-144.

4. Edzwald, J. Principles and applications of dissolved air flotation. Water Sci. Technol. 1995, 31, $1-23$.

5. Metcalf \& Eddy, Inc. Wastewater Engineering: Treatment and Reuse, 4th ed.; McGraw Hill: New York, NY, USA, 2003 
6. Ross, C.; Smith, B.; Valentine, G. Rethinking dissolved air flotation (DAF) design for industrial pretreatment. In Proceedings of $2000 \mathrm{WEF}$ and Purdue University Industrial Wastes Technical Conference; St. Louis, MO, USA, May 2000; Water Environment Federation: Alexandria, VA, USA, 2000; pp. 43-56.

7. Sarrot, V.; Huang, Z.; Legendre, D.; Guiraud, P. Experimental determination of particles capture efficiency in flotation. Chem. Eng. Sci. 2007, 62, 7359-7369.

8. Han, M.; Kim, T.; Kim, J. Effects of floc and bubble size on the efficiency of the dissolved air flotation (DAF) process. Water Sci. Technol. 2007, 56, 109-115.

9. Faust, S.; Aly, O. Chemistry of Water Treatment, 2nd ed.; Ann Arbor Press: Chelsea, MI, USA, 1997.

10. Haarhoff, J.; van Vuuren, L. Design parameters for dissolved air flotation in South Africa. Water Sci. Technol. 1995, 31, 203-212.

11. Haarhoff, J.; Rykaart, E. Rational design of packed saturators. Water Sci. Technol. 1995, 31, 179-190.

12. Steinbach S.; Haarhoff J. A simplified method for assessing the saturation efficiency at full-scale dissolved air flotation plants. Water Sci. Technol. 1998, 38, 303-310.

13. Haarhoff, J.; Steinback, S. A model for the prediction of the air composition in pressure saturators. Water Res. 1996, 30, 3074-3082.

14. De Rijk, S.; Jaap, G.; den Blanken, J. Bubble size in flotation thickening. Water Res. 1994, 28 , 465-473.

15. Rubio, J.; Souza, M.; Smith, R. Overview of flotation as a wastewater treatment technique. Miner. Eng. 2002, 15, 139-155.

16. Deacon, E. Gas transfer to and across an air-water interface. Tellus 1977, 29, 363-374.

17. Broecker, W.; Peng, T. Gas exchange rates between air and sea. Tellus 1974, 26, 21-35.

18. Vlyssides, A.; Mai, S.; Barampouti, E. Size distribution formed by depressurizing air-saturated water. Ind. Eng. Chem. Res. 2004, 43, 2775-2780.

19. Wang, L.; Ouyang, F. Hydrodynamic characteristics of the process of depressurization of saturated water. Chin. J. Chem. Eng. 1994, 2, 211-218.

(C) 2012 by the authors; licensee MDPI, Basel, Switzerland. This article is an open access article distributed under the terms and conditions of the Creative Commons Attribution license (http://creativecommons.org/licenses/by/3.0/). 